\title{
RECENT ADVANCES IN THE BIOCHEMISTRY OF THE VITAMIN B COMPLEX AND THEIR CLINICAL IMPORTANCE:
}

\author{
By J. NORMAN DAVIDSON, B.Sc., M.B., Ch.B. \\ (Lecturer in Biochemistry, Physiology Department, University College, Dundee, \\ The University of St. Andrews.)
}

Within the last few years our knowledge of vitamins has made enormous strides. Many of them have now been isolated, at least six of them have been synthesised, and it is now possible to regard them not so much as mysterious unknown agents but much in the same way as we regard the essential amino acids, i.e. as substances essential for the well-being of the body which the body cannot synthesise for itself and which must therefore be taken in the food.

Within the last few months the position of the vitamin B group has been considerably extended and modified. Originally vitamin B was a substance found in the husks of cereals which prevented beri-beri; but by I925, chiefly owing to the work of Goldberger of the United States Public Health Service, the conclusion had been reached that pellagra was also a disease due to a vitamin deficiency, and that the vitamin which was necessary for its prevention and cure was very similar to the vitamin B which prevented beri-beri. For example fresh yeast could prevent both diseases but if the yeast were first autoclaved, it could no longer prevent beri-beri although it still retained its power to prevent pellagra. Goldberger therefore came to the conclusion that vitamin B consisted of at least two components, vitamin $B_{1}$ which prevented beri-beri and vitamin $B_{2}$ which prevented pellagra. These vitamins are sometimes referred to in the American literature as $F$ and $G$ respectively.

\section{Vitamin $\mathbf{B}_{\mathbf{2}}$.}

Human beri-beri usually occurs in two main types, a wet type in which there is gross œdema of the tissues, and a dry type with extensive atrophy of the muscles. The heart is dilated and hypertrophied but perhaps the most characteristic feature is a severe multiple neuritis. A similar polyneuritic condition also occurs in fowls which have been fed on a diet of polished rice. Eijkmann of the Dutch Medical Service in Java showed in 1897 that the condition could be prevented and cured by the addition of the rice polishings or of an alcoholic extract of the polishings. Within the last few years it has been found possible to concentrate the vitamin from rice polishings and to isolate it in the pure crystalline form. Its constitution was determined in I936 by Williams and his collaborators in America who showed that it contains both the pyrimidine and the thiazole ring systems.<smiles></smiles>

The pure vitamin has been given the name aneurin in Europe on account of its antineuritic properties, but in America it is known as thiamin owing to the presence of the thiazole ring.

Once the constitution of the substance was known the next step was to synthesise it, and the synthesis was achieved in I936 by Williams and Cline,

* An address delivered to the Forfarshire Medical Association on 17th January, 1939. 
although an alternative method was published shortly afterwards by Todd and Bergel in Edinburgh.

Many methods have been developed for assaying the vitamin. One of the simplest is a direct chemical estimation made by oxidising the vitamin to the pigment thiochrome which is extracted and estimated colorimetrically or photometrically (Jansen, I936, and Marrack and Höllering, I939). Another depends upon the fact that the vitamin will abolish the bradycardia present in rats which have been nourished on a vitamin $B_{1}$ free diet (Birch and Harris, I934). Other methods depend upon the power of the vitamin to promote the growth of the mould Phycomyces Blakeseeanus (Meiklejohn, I937), or to increase the oxygen uptake of avitaminous pigeon brain slices (Peters, I935) (catatorulin test).

As the result of these methods the vitamin $B_{1}$ content of various foods has been estimated (Table I) and the amounts which it is desirable to have in the diet have been ascertained. It is found most abundantly in the germ of wheat or rice grain, but it is also present in yeast, liver, egg yolk, cereals and nuts. Milk contains very little and one quarter of this small amount is destroyed on pasteurisation. Wholemeal bread contains a considerable amount of the vitamin but white bread contains little or none. The vitamin is easily destroyed by heat, and alkali, but is stable in acid solution.

For some years now it has become apparent that a condition of hypovitaminosis $B_{1}$ is much commoner in Western Europe than might be expected, and this has been borne out by measurements of vitamin $\mathbf{B}_{1}$ excretion in the urine (Harris et al, I938). The chief sufferers are children. Controlled experiments have been performed on large numbers of children (Ross and Summerfeldt, I935) and it has been shown that those who receive extra vitamin $\mathbf{B}_{1}$ gain in weight more rapidly and have much better appetites than their less fortunate fellows who must do without. Whether the same state of affairs holds for adults also is rather more difficult to prove but there is a group of conditions in which symptoms of vitamin $B_{1}$ deficiency may develop not so much on account of lack of vitamin $B_{1}$ in the diet but because the appetite is poor and little food is ingested or because the vitamin fails to be absorbed from the gastro-intestinal tract, e.g. in cases of achlorhydria.

For example chronic alcoholism is a condition in which vitamin $B_{1}$ deficiency may arise from these causes, and therefore alcoholic polyneuritis is often relieved by the parenteral administration of vitamin $B_{1}$ (Joliffe and Colbert, I936). Similarly the polyneuritis which occurs in pregnancy may benefit by vitamin $\mathrm{B}_{1}$ therapy (Theobald, I936). In this case a hypovitaminosis may be caused by the increased requirements of pregnancy or by a diminished food intake due to hyperemesis.

Ritchie Russell has described several cases in which vitamin $\mathbf{B}_{\mathbf{1}}$ administered parenterally has been used with great success in the treatment of subacute combined degeneration of the spinal cord, and he has also found it valuable in cases of prolonged anorexia (Russell, I936).

One of the characteristic features of vitamin $B_{1}$ deficiency is intestinal stasis and it has often been suggested that the frequency of constipation and allied disorders in man may be due to a lack of vitamin $B_{1}$. Whether or not this is so is a matter which is difficult to prove but there are many reports of success in the treatment of constipation by means of vitamin $B_{1}$ (Joslin and Helms, I937).

The question of course arises-how does vitamin $B_{1}$ act in the body? It has been known for some time that in cases of beri-beri there is an increased amount of lactic acid in the blood and that after exercise the blood lactic acid 
rises to a very high level which is maintained for a long period. It has also been found by Peters and his colleagues that there is an increased amount of $\stackrel{D}{2}$ lactic acid in the brain of pigeons suffering from polyneuritis due to vitamin $B_{1}$ deficiency (Kinnersley and Peters, I929). Brain slices from such pigeons show a diminished oxygen uptake, but if vitamin $B_{1}$ is added to the slices in vitro the oxygen uptake can be increased to the normal level and the accumulated lactic acid disappears (Gavrilescu and Peters, I93I). Not only lactic acid but also pyruvic acid accumulates in polyneuritic birds. It appears therefore that in the absence of vitamin $B_{1}$ lactic and pyruvic acids cannot be dealt with in the normal fashion.

Recently it has been found possible to isolate from yeast the diphosphate of vitamin $B_{1}$ (Lohmann and Schuster, I937), and this compound has been shown to act as a coenzyme to the enzyme carboxylase which is necessary for the oxidation of lactic and pyruvic acids. Vitamin $B_{1}$ therefore acts in the form of its diphosphate as a co-carboxylase. In the normal course of events in carbohydrate metabolism lactic and pyruvic acids are oxidised to break down products under the influence of carboxylase and its coenzyme. If vitamin $B_{1}$ is lacking in the diet sufficient of the coenzyme is not produced and the oxidation is deficient. Laciic and pyruvic acids therefore accumulate in the body.

The mode of action of vitamin $B_{1}$, therefore, or at least one mode of action, is to function as a component of a coenzyme necessary for certain stages in carbohydrate metabolism.

\section{Vitamin $\mathbf{B}_{\mathbf{2}}$.}

Pellagra is a disease which is comparatively seldom seen in Britain but ifơ other parts of the world it constitutes a serious medical problem and also at: important economic problem because it occurs among populations which are forcest by economic depression to subsist on a very badly balanced diet which consists mainly of maize. It is found in Italy, in Roumania, and in Egypt but it occurs most commonly among the negro population of the U.S.A. and as a cause of death it ranks high in the statistics in the southern states. Clinically it is characterised by dermal lesions which are found, chiefly in the summer months, on parts of the skin which are exposed to the sun's rays, e.g. the face and neck, the back of the hand and the dorsum of the foot. Alimentary disturbances include stoma. titis and acute glossitis and a severe non-fatty diarrhoea which is very persistent. There may be achlorhydria and secondary anæmia. There are also mental features, depression, insomnia, irritability and restlessness leading on to melancholia and dementia, and sometimes there are nervous manifestations resembling those of subacute combined degeneration of the spinal cord. One peculiar feature which is present in many cases is the occurrence of porphyrins in the urine.

Until a few years ago pellagra was supposed to be due to bad hygiene or to infection, but Goldberger was able to prove that this was not the case and that the real fault lay in the diet. He showed that the incidence of pellagra could be greatly reduced by improving the diet particularly by the addition of fresh meat and eggs, and that the disease could be produced in human beings by dietary measures alone. The non-infective nature of the disease was demonstrated by its failure to develop in normal individuals who tried to infect themselves by means of the excretions of pellagrins.

Goldberger therefore came to the conclusion that pellagra was a deficiency disease due to lack of what came to be called vitamin $B_{2}$. This vitamin appeared to be quite distinct from vitamin $B_{1}$ since its stability to heat is very much greater than that of the anti-beri-beri factor. The next step was to concentrate vitamin $\mathbf{B}_{2}$, 
to try to isolate and to determine its chemical nature. To facilitate the testing of vitamin $\mathbf{B}_{\mathbf{2}}$ concentrates attempts were made to produce experimental pellagra or allied conditions in animals and it was found that if dogs were fed on a diet free from vitamin $\mathbf{B}_{\mathbf{2}}$ they developed a condition called blacktongue which is very similar to human pellagra especially as regards the alimentary disturbances, and which appears to be the exact analogue of human pellagra (Goldberger and Wheeler, I928). This was therefore a condition in which vitamin $B_{2}$ concentrates could be tested.

As the purification of the vitamin proceeded it soon became evident that vitamin $B_{2}$ was not a single substance but a group of substances.

The first substance to be isolated from vitamin $B_{2}$ concentrates was a yellow pigment called lactoflavin or riboflavin which is present in yeast, whey, meat and eggs (Table II) and which has been shown to have the following structure:-

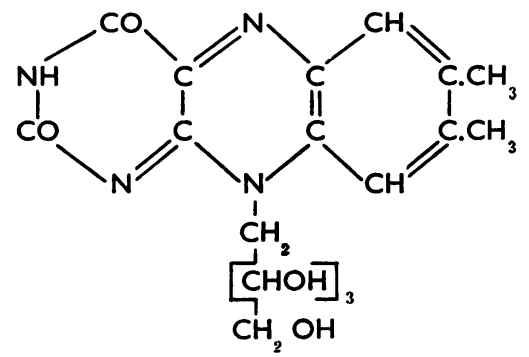

In the body it unites with phosphoric acid to form lactoflavin phosphate which combines with a specific protein to form the "yellow enzyme" of Warburg. which is essential for certain intracellular oxidative processes (Theorell, I937).

When lactoflavin was isolated it was at first thought that vitamin $\mathbf{B}_{2}$ itself had been isolated in the pure state, but it soon became evident that lactoflavin was not the pellagra preventing substance. If it was given to rats which had been fed on a pellagra producing diet and which therefore suffered from dermatitis and stunted growth, it produced normal growth but left the dermatitis unaffected nor had it any effect on canine blacktongue or human pellagra. Lactoflavin was not therefore the pellagra preventing vitamin but was a vitamin necessary for growth in the rat.

The next step in the investigation of vitamin $\mathrm{B}_{2}$ came towards the end of 1937 . again from America. Elvehjem and his colleagues had been working on vitamin $\mathrm{B}_{2}$ concentrates which they prepared from liver and from these they succeeded in isolating the amide of nicotinic acid.

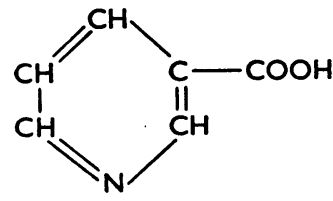

Nicotinic Acid.

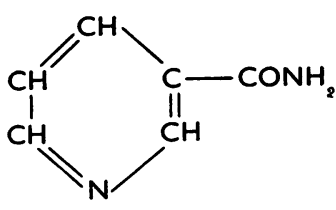

Nicotinic acid amide.

Both nicotinic acid and its amide were tested on dogs suffering from blacktongue with dramatic results. A single dose of $30 \mathrm{mg}$. caused the mouth lesions to disappear in less than two days, the appetite improved immediately and normal growth was resumed. Dogs kept on a Goldberger pellagra producing diet with the addition of $30 \mathrm{mg}$. every second day grew well and appeared normal in every way while control dogs showed typical blacktongue. 
A condition similar to blacktongue has also been produced in pigs in this country by Dr. Hariette Chick and Sir Charles Martin (r938). On a Goldberger $\stackrel{\circ}{?}$ diet the pigs developed severe diarrhœa, loss of appetite and a severe dermatitis with loss of hair. When the animals were almost at the point of death they were given nicotinic acid by injection, at first I00 $\mathrm{mg}$. and later $60 \mathrm{mg}$. daily. The appetite returned within 24 hours, the diarrhoea disappeared, and after a week the scabs on the skin had gone. After six weeks on the same diet with nicotinic acid added, the pigs were in a normal healthy condition.

A pellagra-like condition has also been produced in monkeys by Harris in the Nutrition Laboratory in Cambridge (I938). On a Goldberger diet the animals developed a condition similar to human pellagra and this condition was completely cured by the administration of nicotinic acid in doses as small as $5 \mathrm{mg}$. daily.

The success with which these conditions in animals were treated with nicotinic acid prompted clinicians to try its effect in cases of pellagra in man and towards the end of 1937 reports of its action appeared almost simultaneously from three different sources (Smith et al, 1937; Fouts et al, 1937; Spies et al, 1938). In most cases the patients were first of all placed on a diet free from vitamin B for several days, and during this time their condition remained constant or deteriorated. Nicotinic acid in doses of $\frac{1}{2}-\mathrm{I}$ gram. daily was then administered, and within 48 hours a distinct improvement resulted. The diarrhoea and the stomatitis rapidly disappeared and in less than three weeks the dermatitis had also cleared up.

Since the appearance of these preliminary accounts reports have come in fron many sources on the employment of nicotinic acid in the treatment of pellagres and these reports show a striking degree of unanimity. In nearly every case a marked improvement in the patient's condition has appeared within 48 hours and the final results have almost always been satisfactory. It is sometimes found that the nervous symptoms are not affected by nicotinic acid but in these cases an associated vitamin $B_{1}$ deficiency can often be detected and the administration of aneurin will produce a marked improvement in the condition of the nervous system.

The most active worker in this field has been Spies (1938). Recently he has reported on the treatment of 73 cases of pellagra with nicotinic acid (I938). In each case striking improvement was observed even within the first 24 hours and usually a complete cure was obtained within a few weeks.

In assessing the value of all these reports it is important to remember that although the use of nicotinic acid on an extensive scale has been limited to a certain extent to a few areas in the United States the effectiveness of the substance has been proved not just in a few cases but in several hundreds. Moreover confirmatory reports are now coming in from a much wider area, not only from America but from Egypt and the Near East. For example, Alport and his colleagues (I938) have recently reported on I7 cases in Egypt which responded to nicotinic acid with satisfactory results although not so rapidly as previous observers had claimed.

Nicotinic acid is usually administered in an amount of 0.5 gram daily divided into five doses of Ioo mg. each. Occasionally its administration is followed by a slight reaction, with flushing and itching and tingling sensations on the face and extremities, but these effects are never severe and usually pass off within 20 minutes. As yet no satisfactory figures are available to show the nicotinic acid content of various foodstuffs but it is known to be present in yeast, 
fresh meat, liver, kidneys and eggs and to a lesser extent in milk and cheese, while butter, cabbage and white flour are known to be poor sources. The content of nicotinic acid amide in certain tissues is shown in Table III.

On a Goldberger diet monkeys, pigs, and dogs develop pellagra-like conditions which can be cured by the administration of nicotinic acid. When rats are fed on such a diet they cease to grow and develop a severe pellagra like dermatitis. If lactoflavin is administered growth is stimulated but the dermatitis is unaffected, and it remains unaffected on the administration of nicotinic acid. Rat pellagra, therefore, is caused by lack of yet another vitamin and this vitamin is known as $B_{6}$ although it is really a component of the vitamin $B_{2}$ complex. As yet its composition is unknown* but it has recently been obtained by several different investigators in the pure crystalline state (Györgyi, I938; Keresztesy and Stevens, I938) and has been given the name adermin (Kuhn and Wendt, I938). The present state of affairs is, therefore, that the vitamin $\mathbf{B}_{2}$ complex consists of at least three components, lactoflavin, nicotinic acid, and adermin or vitamin $\mathbf{B}_{6}$. A fourth component which differs from adermin in not being adsorbed on fullers earth and which is required for the prevention of a pellagra-like condition in chicks, is also known and is referred to in the meantime simply as the "filtrate factor" (Lepkowsky and Jukes, I936). The various components of the vitamin $\mathbf{B}_{\mathbf{2}}$ complex are summarised in Table IV.

It is interesting to note that nicotinic acid is by no means a recently discovered substance. It has of course been known to chemists for a long time as one of the degradation products of nicotine, but it was first isolated from natural products by some Japanese workers in IgI2 and a year later it was actually isolated from the vitamin fraction of rice polishings by Funk who was attempting at that time to isolate the anti-beri-beri vitamin (I9I3). Since the substance was inactive against beri-beri Funk's discovery received little credit although nicotinic acid was tested out, with negative results, during the war by Williams in America as a cure for polyneuritis, and it was not until I935 that nicotinic acid again came into the limelight when it was isolated from an animal source, heart muscle, by Kuhn in Heidelberg.

About the same time Warburg (I938) in Berlin had isolated from the red blood cells of the horse a coenzyme which was necessary for the oxidation of certain carbohydrate derivatives, in particular hexose monophosphate, and this coenzyme could be broken down by hydrolysis into one molecule of nicotinic acid amide, one molecule of adenine, two molecules of ribose and three of phosphoric acid. Warburg showed that this coenzyme could, after being bound to a specific protein, bring about the oxidation of hexose monophosphate by removing two atoms of hydrogen from it. In this process the hydrogen atoms become attached to the pyridine ring of the nicotinic acid amide. These two atoms of hydrogen are then passed on to lactoflavin phosphate attached to another specific protein in the form of the "yellow enzyme." The "yellow enzyme" in its turn then passes on the hydrogen to the oxidised form of the intracellular respiratory pigment cytochrome which completes the process by allowing the hydrogen to react with oxygen to form water.

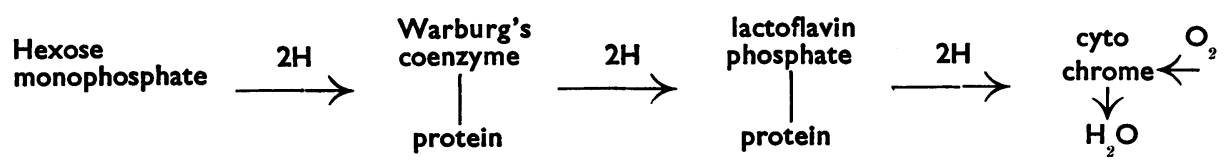

\footnotetext{
*It has recently been shown by Kuhn (Ber. d. deutsch. chem. Ges. 1939, 72, 310), that adermin is 3-hydroxy 4:5-dihydroxymethyl 2-methyl pyridine.
} 
Now this type of oxidation system is found in many animal cells and one function of nicotinic acid therefore is to act as a component of this coenzyme which plays such an important part in intracellular oxidations.

About the same time as Warburg made his discovery, von Euler in Stockholm succeeded in isolating another coenzyme, cozymase, which is essential in the process of alcoholic fermentation by yeast (I935). Cozymase was found to contain nicotinic acid amide, adenine, two molecules of ribose and two of phosphoric acid. It differs therefore from Warburg's coenzyme in containing one phosphoric acid molecule less. It has been known for some time to be essential in the process of alcoholic fermentation but it is now known to be essential also in the series of chemical changes which accompany muscular contraction.

When nicotinic acid is administered to pellagrins the content of cozymase in the blood is found to increase (Vilter et al, I939).

Curiously enough it has recently been shown that either cozymase or Warburg's coenzyme can act as the $\mathrm{V}$ factor which is necessary for the growth of H. influenzæ (Lvov; A. \& M., I937), while nicotinic acid itself is a factor necessary for the growth of the diphtheria bacillus (Mueller, I937), and certain strains of lactic acid bacillæ while together with vitamin B it forms the staphylococcus growth factor (Knight, I937). Another organism which requires nicotinic acid for growth is Proteus (Fildes, 1938), which converts it into either Warburg's coenzyme or cozymase.

The present position appears to be therefore that nicotinic acid is the pellagra preventing vitamin or at least part of it and that one function of it in the body is to act as a component of two coenzymes which are necessary for certain funda mental intracellular chemical processes. Vitamin $B_{1}$ and lactoflavin also act as essential components of enzyme systems. Whether or not the connection between vitamins and enzyme systems gives us the key to the elucidation of the true nature of the physiological action of vitamins remains to be seen.

TABLE I.

(From Boas Fixsen and Roscoe, 1938).

Vitamin $B_{1}$ content of foodstuffs.

International Units per 100 grams.

One International Unit is equivalent to $0.003 \mathrm{mg}$. crystalline aneurin.

\begin{tabular}{|c|c|c|c|c|}
\hline Wheat (germ) & $\ldots \quad 400-2,200$ & Nuts & $\ldots$ & $80-320$ \\
\hline Yeast (dried) & $\ldots \quad 310-1,000$ & Beef (lean) & $\ldots$ & $30-100$ \\
\hline Oatmeal ... & 325 & Fruits & $\ldots$ & $30-60$ \\
\hline Wheat (whole grain) & ... $118-340$ & Bread (wholemeal) & $\ldots$ & $75-130$ \\
\hline Ox liver (cooked) & 150 & Bread (white) & $\ldots$ & $12-30$ \\
\hline Egg yolk ... & 100 & Raw milk (cow's) & $\ldots$ & 23 \\
\hline
\end{tabular}

TABLE II.

(From Boas Fixsen and Roscoe, 1938).

Lactoflavin content of foods

mg. per $100 \mathrm{gm}$.

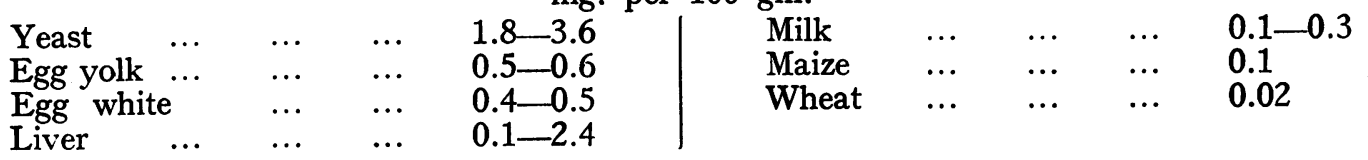




\section{TABLE III.}

(From Karrer and Keller, 1938).

Nicotinamide content of tissues

mg. per kilo.

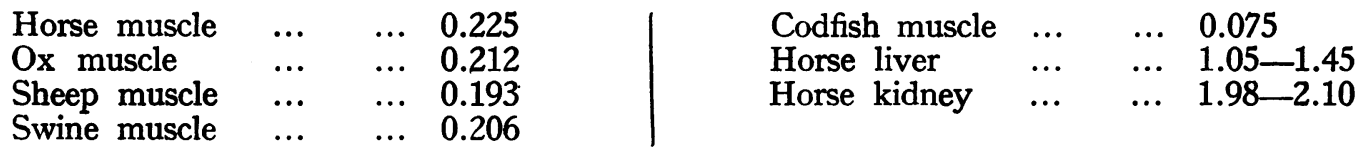

\section{TABLE IV.}

Possible mode of action.

Vitamin $B_{1}$ (aneurin)

Vitamin $\mathrm{B}_{2}$ complex lactoflavin

nicotinic acid

$\operatorname{adermin}\left(B_{6}\right)$

filtrate factor
Aneurin diphosphate acts as cocarboxylase necessary for disposal of lactic and pyruvic acids.

As a component of the "yellow enzyme " in intracellular oxidations.

As a component of two coenzymes for hydrogen transfer in intracellular oxidations.

Unknown.

Unknown.
Result of deficiency.

Beri-beri Polyneuritis.

Defective growth in rat and dog.

Human pellagra, canine blacktongue and analogous disorders in monkeys and pigs.

Dermatitis in rats.

Dermatitis in chicks.

Defective growth in rat and chick.

REFERENCES

ALPORT, A. C., GHALROUNGUI, P. and HARINA, G. (1938), The Lancet, 2, 1460.

BIRCH, T. W. and HARRIS, L. J. (1934), Biochem. J., 28, 602 .

BOAS FIXSEN, M. A. and ROSCOE, M. H. (1938), Nutr. Abs. Rev., 7, 823.

CHICK, H., MACRAE, T. F., MARTÍN, A. J. P. and MARTIN, C. J.' (1938), Biochem. J., $32,10$.

ELVEHJEM, C. A., MADDEN, R. J., STRONG, F. M. and WÓLLLEY, D.'W. (1938), J. Biol. Chem., 123, 137.

EULER, H. von, ALLBERS, H. and SCHLENK, F. (1935), Z. Physiol. Chem., 237, 1.

FILDES, P. (1938), Brit. J. Exp. Path., 19, 239.

FOUTS, P. J., HELMER, O. M., LEPKÖWSKY, S. and JUKES, T. H. (1937), Proc. Soc. Exp. Biol. and Med., $37,405$.

FUNK, C. (1913), J. Physiol., 46, 173.

GAVRILESCU, N. and PETERS, R. A. (1931), Biochem. J., 25, 2150.

GOLDBERGER, J. and WHEELER, G. A. (1928), U.S. Pub. Health Rep., 43, 172.

GRANT, J. M., ZSCHIESCHE, E. and SPIES, T. D. (1938), The Lancet, $1,939$.

GYORGYI, P. (1938), J. Amer. Chem. Soc., 60, 983.

HARRIS, L. J. (1938), Biochem. J., 32, 1478.

HARRIS, L. J., LEONG, P. C. and UNGLEY, C. C. (1938), The Lancet, 1, 539

JANSEN, B. C. P. (1936), Rec. Trav. Chim., 55, 1046

JOLIFFE, N. and COLBERT, C. N. (1936), J. Amer. Med. Assoc., 107, 642.

JOSLIN, C. L. and HELMS, S. T. (1937), Arch. Pediat., 54, 533.

KARRER, P. and KELLER, H. (1938), Helv. Chim. Acta, 21, 1070.

KERESZTESY, J. C. and STEVENS, J. R. (1938), Proc. Soc. Exp. Biol. and Med., 38, 64

KINNERSLEY, H. W. and PETERS, R. A. (1929), Biochem. J., 23, 1126.

KNIGHT, B. C. J. G. (1937), Biochem. J., 31, 731.

KUHN, R. and WENDT, G. (1938), Ber'd. deutsch. Chem. Ges., 71, 1118

LEPKÓWSKY, S. and JUKES, T. H. (1936), J. Biol. Chem., 114, 109.

LOHMANN, K. and SCHUSTER, P. (1937), Biochem. Zeit., 294, 1888.

LVOV, A. and LVOV, M. (1937), Proc. Roy. Soc. [B] 122, $352,360$.

MARRACK, J. and HÖLLERING, Y. F. (1939), The Lancet, $1,325$.

MEIKLE JOHN, A. P. (1937), Biochem. J., 31, 1441

MUELLER, J. H. (1937), J. Bact., 34, $42 \dot{9}$.

PETERS, R. A. (1935) Biochem. J., $29,712$.

ROSS, T. and SUMMERFELDT, P. (1935), Amer. J. Dis. Child., 49, 485.

RUSSEL, W. R. (1936), Edin. Med. J., 43, 815.

SMITH, D. T., RUFFIN, J. M. and SMITH, S. G. (1937), J. Amer. Med. Assoc., 109, 2054.

SPIES, T. D., BEAN, W. B. and STONE, R. E. (1938), J. Amer. Med. Assoc., ill, 589.

SPIES, T. D., COOPER, C. and BLANKENHORN, M. A. (1938) J. Amer. Med. Assoc., $110,622$.

THEOBALD, G. W. (1936), The Lancet, 1, 834.

THEORELL; H. (1937), Ergeb. d. Enzymforsch, 6, 111

TODD, A. R. and BERGEL, F. (1937), J. Chem. Soc., 364

VILTER, R. W., VILTER, S. P. and SPIES, T. D. (1939), J. Amer. Med. Assoc., 112420.

WARBURG, O." (1938), Ergeb. der Enzymforsch, 7, 210.

WILLIAMS, R. R. (1936), J. Amer. Chem. Soc., 58, 1063.

WILLIAMS, R. R. and CLINE, J. K. (1936), ibid, 58, 1504. 